ARA-C (total dose $6 \mathrm{mg} / \mathrm{kg}$ ). This treatment was repeated three weeks later and he had passed into full remission by January 1971. Remission was maintained by weekly immunotherapy with B.C.G and allogeneic leukaemia cells and monthly courses of chemotherapy. The chemotherapy consisted of five daily injections of ARA-C 1-2 mg/kg together with either a single injection of daunorubicin $1.5 \mathrm{mg} / \mathrm{kg}$ or 6 -thioguanine $2 \mathrm{mg} / \mathrm{kg}$ per day for five days. After four such courses he developed burning sensations in his feet which followed each subsequent course of treatment but gradually improved between courses. Because this occurred after every course it could be related only to the ARA-C. Chemotherapy was stopped on 26 November 1971 after a total dose of $7 \mathrm{~g}$ of ARA-C, but he continued to complain of intermittent but he continued to complain of intermittent burning or tingling sensations in his feet, sometimes knee and occasionally affecting the fingers. There knee and occasionally affecting the fingers. There
has never been any objective neurological abnorhas never been any objective neurological abnor-
mality and his symptoms have continued to improve slowly, but they are still present $2 !$ years after stopping chemotherapy.

Case 2-A 52-year-old man with acute myelogenous leukaemia (weight $70 \mathrm{~kg}$ ) had similar induction chemotherapy to Case 1 and after $600 \mathrm{mg}$ of ARA $\mathrm{c}$ hother $600 \mathrm{~m}$ of ARA-C he complained of numbness and paraesthesiae involving all four limbs. After four courses of treatment he passed into full haematological remission and was then given eight weeks' treatment with 6-thioguanine and cyclophosphamide. This was immediately followed by a single injection of daunorubicin $100 \mathrm{mg}$ and ARA-C $130 \mathrm{mg}$. He then stopped all chemotherapy and was maintained in complete remission on immunotherapy alone. During this period his neurological symptoms improved, though he still complained of painful intermittent paraesthesiae in a glove-andstocking distribution extending to the elbows and knees and intermittent stabbing pains throughout the body. He relapsed after seven months of immunotherapy and was treated with two courses immunotherapy and was treated with two courses of high-dose ARA-C (total $20 \mathrm{mg} / \mathrm{kg}$ ) followed by single intravenous injection of adriamycin $(2 \mathrm{mg}$ $\mathrm{kg}$ ). These courses were given 10 days apart and following the second course his paraesthesia became worse. Thereafter aggravation of his neurological symptoms was always associated with ARA-C. A second complete remission lasted only three months in spite of monthly courses of ARA-C $2 \mathrm{mg} / \mathrm{kg}$ for five days and 6-thioguanine alternating with daunorubicin. Reinduction chemotherapy included ARA-C ( $180 \mathrm{mg} / \mathrm{daily}$ for five days) following which his neurological symptom rapidly became worse and their character changed. $\mathrm{He}$ continued to have numbness extending up to the elbows and knees and tingling sensations in the fingers, but he also had burning or aching pains with the same distribution. At no time auring the with the same distribution. At no time auring the neurological abnormalities. He died five months neurological abnormalities. He died

Both of these patients had symptoms characteristic of a sensory peripheral neuropathy which developed during cytotoxic therapy for acute myelogenous leukaemia. In both cases the only drug consistently related with deterioration of the neurological symptoms was ARA-C. Case 1 would appear to have developed these symptoms after a total of $4 \mathrm{~g}$ of ARA-C, but because of their subjective nature the time of onset was difficult to determine precisely. Case 2 developed his neurological symptoms after a total dose of $600 \mathrm{mg}$ of ARA-C. Both patients reported improvement in the absence of chemotherapy, but Case 1 still experiences some paraesthesiae two and a half years after his last dose of ARA-C.

During the past six years at least 350 new adult patients with leukaemia have been treated with ARA-C in our departments, of whom approximately $40 \%$ have had main tenance ARA-C after remission. This mean that the incidence of problems due to this particular complication is very low. Never theless, there is no question that the quality of life was impaired considerably in both the patients reported here by their neurological symptoms. We would be most interested to know if other workers who use this drug frequently have noticed a similar association.
We wish to to thank Dr. T. McElwain for permission to publish the second case report.

-We are, etc.,

Immunotherapy Department,

Royal Marsden Hospital,

Sutton, Surrey

J. A. RuSSELL

R. L. Powles

I.C.R.F. Department of Medical Oncology, St. Bartholomew's Hospital, don E.C.1 Weiss, H. D., Walker, M. D., and Wiernik, P. H.,
New England fournal of Medicine, 1974, 291,
75 and 127.

Cutaneous and Ocular Reactions to Practolol

SIR,-I was very interested to read the paper by Dr. R. H. Felix and others ( 9 November, p. 321). I would like to bring up to date a quotation from a publication of mine $^{1}$ which appeared in their discussion section.

I reported an incidence of 3-4\% of positive antinuclear factor (A.N.F.) titre in patients on practolol, but in a retrospective survey of 67 patients taking practolol for angina we found that seven had an A.N.F. titre greater than $1 / 40$, an incidence of $11 \%$. In a prospective survey of 71 patients who were treated with practolol for angina or dysrhythmias the A.N.F. titre was greater than $1 / 40$ before treatment in only one $(1.4 \%)$. After an average of six months of treatment this had risen to five $\left(11^{\prime}(1)\right)$ and one of these patients developed a florid disseminated lupus erythematosus (D.L.E.).

A prospective study of 50 patients receiving oxprenolol for the treatment of hypertension revealed no instance of a raised A.N.F. titre before or after treatment for a period of three months. The same was true for 24 patients taking propranolol for hypertension. There have been no instances of D.L.E. syndrome in these two groups of patients.

These observations suggest that practolol is unique among the commonly used betablocking agents in producing the D.L.E. syndrome and in producing a rising A.N.F. titre.-I am, etc.,

Northwick Park Hospital,

E. B. RAFTERY

1 Raftery, E. B., in New Perspectives in Betablockade International Symposium, p. 239.
Denmark. Ciba Laboratories, 1972.

\section{Ischaemic Heart Disease in Young Women}

SIR,-In his analysis of ischaemic hear disease in young women Dr. M. F. Oliver (2 November, p. 253) claims that there had been a hypertensive "risk factor" in $40 \%$ of those who suffered myocardial infarction. This figure, I would suggest, is misleading since the evidence, much of it retrospective is insufficient to establish that these women were hypertensive before their infarctions.

An unstated proportion of them were "recorded as having hypertension" for no bette reason than that they had been under treatment for this condition apparently at the hands of their family doctor, there being no reference to any earlier attendance in Dr. Oliver's department. In others the diagnosis was made on the strength of a clinic finding of a diastolic pressure that remained at a level of $100 \mathrm{~mm} \mathrm{Hg}$ or more during a period of ten minutes rest on one occasion. A single such reading in women aged up to 45 may suggest but cannot justify a diagnosis of hypertension. Still less is it relevant that in the remainder of this group the pressure was found to have risen into similar levels within a year after the infarction.

It is said of the allegedly hypertensive patients who sustained infarcts that $25 \%$ also had left ventricular hypertrophy, the implication being that here was further proof of pre-existing hypertension. We are not told how the hypertrophy was recognized. But in patients who had survived, or were about to suffer, infarction the assumption would appear to be precariously based. Radiologically it is seldom possible to make an exact distinction between minor cardiac enlargement caused by hypertension and that also found in normotensive patients with myocardial change secondary to coronary artery disease. Nor do electrocardiographic tracings afford any precise means of distinguishing between the two, especially in terms of S-T depression and $T$ inversion, the only abnormalities that are cited.

That hypertension after infarction was later found to be a "potent risk factor" is scarcely surprising since it was imposing strain upon a myocardium that was already damaged, a simple sequence of cause and effect unrelated to those obscure and diverse influences that determine the slow development of coronary atheroma together with its allied, yet nonetheless distinct, occasional complication of myocardial infarction.-I am, etc.,

I. MCD. G. STEWART

Victoria Hospital,

Blackpool

\section{Impaired Colour Vision in Diagnosis of} Digitalis Intoxication

SIR,-Measurement of the serum level of digoxin provides an accurate estimate of the diagnosis of digitalis intoxication. ${ }^{12}$ Measurements are, however, time-consuming and need expensive instrumentation. Simple methods for the confirmation of digitalis intoxication would be welcome.

Various visual complaints are frequently seen as initial signs of digitalis toxicity. ${ }^{3}$ We have tested colour vision in five consecutive ambulant patients in whom the suspicion of digitalis intoxication arose because of clinical signs like loss of appetite, nausea, abdominal discomfort, extrasystoles, or unexplained feeling of sickness. In two patients barium meal examination, carried out because of loss of weight and constant abdominal discomfort, had revealed no signs of organic disease. In the examination of colour vision Ishihara tables (24 plates, 1974) were used. The patients (two male, three female, aged 61-78) were receiving $0 \cdot 15$ to $0.75 \mathrm{mg}$ of digoxin daily and two with heart failure were also receiving frusemide with potassium chloride; four had atrial fibrillation. The serum potassium level was normal $(4-2-4 \cdot 6 \mathrm{mmol} / \mathrm{l})$ in all five. The serum digoxin was only $1.3 \mathrm{ng} / \mathrm{ml}$ in one patient but ranged from 2.1 to $3.2 \mathrm{ng} / \mathrm{ml}$ in the other four.

When first studied all five patients had some degree of difficulty in seeing the plates for red-green vision. All also complained of indistinct vision of objects. When the test was repeated two weeks after diminishing the digoxin dose none of the subjects had 
any difficulty in seeing all the plates, while the indistinct vision and other clinical signs of digitalis intoxication had disappeared.

In acute suicidal digitalis poisoning we have found the colour vision test to be of no value, indicating that a certain time is needed for the development of the defect in colour vision. Similarly in cases of intoxication provoked by an apparent hypokalaemia the test has proved unsuitable.

The serum digoxin level of $1.3 \mathrm{ng} / \mathrm{ml}$ in of $2.0 \mathrm{ng} / \mathrm{ml}$ which is customarily regarded one of our patients was well below the level as the threshold for digitalis intoxication. However, even at such low digoxin levels cases of intoxication have been reported. ${ }^{2}$ Cardiac signs of digitalis intoxication are probably based on the inhibition of the transport-related ATPase. ${ }^{5}$ ATPases from various sources show different sensitivities towards inhibition by cardiac glycosides. ${ }^{6}$ It is tempting to assume that the ATPase of the eye may sometimes be even more sensitive than that of the heart, which would contribute to the visual complaints often encountered in digitalis intoxication.

In our study all the patients had been treated with digoxin for long periods when impaired colour vision was demonstrated. None of them was hypokalaemic. In all cases the heart disease and its treatment were fairly stable. In such cases the colour vision test can be used as an additional simple screening test for digitalis intoxication if any suspicion of overdosage is aroused.-I am, etc.,

First Department of Med:cine,

Vesa ManNinen

University of Helsinki,

Helsinki, Finland

Butler, V. P., jun., Progress in Cardiovascular Disea-es, $1972,14,571$

. 188.

Lely, A. H., and van Enter,

Gomez, A. L., American Heart foumal, 1972, 84,285 .

Okita, G. T. in Symposium on Digitalis, ed. $\mathrm{O}$

Storstein. S. N. Hauge and L. Storstein, D.

6 Repke, K, personal communication, 1973

\section{Diuretics in Hypertension}

SIR,-Duiretics are widely used in the treatment of hypertension, partly because they counteract the salt and water retention normally associated with effective reduction in blood pressure, but also because thiazides, at least, reduce peripheral vascular resistance through a direct action on arterioles. Dr. $\mathbf{H}$. J. Dargie and his colleagues (9 November, p. 316) confirm the view held by many that a routine potassium supplement is not necessary when a diuretic is given as an adjunct to the treatment of hypertension in otherwise healthy individuals taking a normal diet. Thus a substantial number of patients can be spared some tablets and the country a small expense.

If cost-effectiveness is to become an important factor in our therapeutic decisionmaking, as it should, we should also ask why the authors chose to use frusemide in this situation. Frusemide has been one of the most important therapeutic advances in the past 10 years for the treatment of resistant oedema and for left ventricular failure, but it does not to my knowledge have any proved advantage over thiazides in the treatment of hypertension-indeed, it may be less effective. ${ }^{2}$ The money saved by not giving a potassium supplement is small compared with the expense of choosing an appropriate diuretic. Can we not as prescribing doctors take note that a simple thiazide is at least as good as an other diuretic for the treatment of uncomplicated hypertension and that the cost of bendrofluazide $5 \mathrm{mg}$, for example, is one-quarter of the that of frusemide $40 \mathrm{mg}$ ? -I am, etc.

St. George's Hosp:tal,

Peter RichaRds

London S.W.1

1 Lancet, 1972, 1, 299.
2 Anderson, J., et al., Quarterly fournal of Medi-
cine, 1971, 40, 541 .

Complications of Prostaglandin-induced Abortion

SIR,-I read with great interest the letter of Professors S. M. M. Karim and S. S Ratnam (19 October, p. 161) on cervical rupture during abortion induced by intraamniotic prostaglandins. The authors state rightly that this type of trauma is secondary to excessive uterine stimulation in the presence of unusual cervical resistance and that it is encountered mainly in young primigravidae. The lesion, however, is no limited to patients given $\mathrm{PGF}_{2} \propto$ as cases have already been reported after intraamniotic instillation of $\mathrm{PGE}_{2 .}{ }^{12}$ It is therefore unlikely that the latter compound exerts any protective action in this respect.

May I further point out that two very different lesions are encountered. The first one occurs-before any cervical dilatation has taken place-at the level of the thinnedout posterior isthmic wall. It presents as transverse tear through which fetus and placenta are expelled into the vagina. The tear may extend into the lateral aspects of the isthmic region, leading to partial annula detachment of the cervix. ${ }^{1}$ Even when repaired this lesion may fail to heal and a fistulous tract may develop, interfering with later reproductive performance. The complication can be prevented by examination of the cervix at regular intervals during the course of abortion and, in those cases at risk, by insertion of one or more laminaria tents into the cervical canal. ${ }^{34}$ In case of impending rupture gentle instrumental dilatation of the cervix should be performed immediately.

Very different and of less consequence is the longitudinal tear involving the lateral aspect of an insufficiently dilated cervix during expulsion of the conceptus. This lesion, somewhat comparable to a Dührssen's incision, is easier to repair and, if it does no reach the uterine isthmus, it should not be cause of cervical incompetence.

To the best of my knowledge not a single instance of either type of traumatic lesion to the cervix has been reported after extraamniotic administration of prostaglandins. It is possible that the Foley catheter, usually resorted to when use is made of this route, has a "ripening" effect on the cervix which facilitates dilatation.-I am, etc.,

Department of Obstetrics and Gynaeco'ogy,

J. J. AMY State University 1 Bowen-Simpkins, P., foumal of Obstetrics and 2 Craft, I., Contemporary Ob/Gvn, April 1974. 3 Corson, S. L.., Bolognese. R. J., and Merola, J., 1973.117, 27.

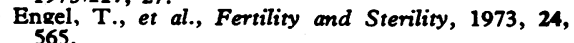

\section{Departmental "Research"}

SIR,-The Department of Health and Social Security has recently commissioned a "research" project to be carried out by Medical Surveys Ltd. I have just received the documents, which contain 20 complicated questions. I am supposed to provide detailed information about certain medical journals, including the British Medical fournal, Prescribers' fournal, Health Trends, Medicine, and the Lancet. I am supposed to answer such questions as how frequently I read these journals, which articles I read, how long I spend reading each journal, how I receive the copy, and what I do with it when I have read it, and many other childish questions which are insulting to one's intelligence.

I am indeed saddened that a member of the medical profession has so much time available to spend on such a useless and expensive exercise. Not only is it a waste of very limited financial resources, but it is this sort of thing which aggravates the acute shortage of paper. It seems to confirm my worst suspicion that the D.H.S.S. employs large numbers of medical administrators who find it hard to occupy their time. They will be well advised to return to the work for which they were trained.-I am, etc.

London $\mathbb{W} .1$

NIGEL H. HARRIS

\section{Place of Diagnostic Radiology in Medicine}

SIR,-I have just read the Langdion Brown Lecture by Dr. J. W. D. Bull (10 August, p. 394). May I reinforce from practical experience the enormous benefits of the many proposals in his thoughtful presentation?

In this new medical school in California radiology is taught almost from the day that the medical student enters the medical school, and it is taught by radiologists. They are in the anatomy class, in the dissecting room, and teaching physiology. (How better to learn how a patient swallows than to see a ciné film of a patient actually swallowing?) The anatomy of the chest, the appearance of the normal chest, and its pathology are taught by radiologists in close cooperation with their pulmonary medicine colleagues and the pathologists. One subject may be taught by all three in the same afternoon. In addition to anatomists and radiologists in the dissecting room there are the appropriate clinicians. A dissection of the knee becomes meaningful when there is an orthopaedic surgeon to answer questions and direct it and a radiologist to demonstrate how the average doctor will see it for the rest of his life.

In the hospital the same principle applies and in my department three or more conferences are held daily to review the films from different clinical areas. Radiologists are always available in the department and, moreover, decide what films are taken. They do not accept "orders" but examine "requests." By thus taking more responsibility they become better radiologists, more aware of what they are doing for their patients, and take more personal interest in the patients themselves. Almost the least important part of their work is the written report on the radiographs. Providing the clinicians with consultation and help follow- 